\title{
Discourses of Position: Ideology and Situation in Italy
}

\author{
MICHAEL STANTON \\ Tulane University \\ USA
}

It is inevitable that buildings relate in tangible ways to their users. While the initial proposition may verge on the axiomatic, the ensuing discussion need not remain so, for it is richly joined to the very nature of significance and to the roots of ideology. The physical qualities of the dialogue between building and body, the relations of thing to perceiving subject, seem some of the least revocable aspects of the complex play of signification and appropriation that characterizes architectural thinking and practice. This essay will discuss some of the moments in the arts when these are presented with particular acuity.

The ensuing investigation of physical phenomena will largely center on their impact upon, or perpetuation of, ideological systems. This by no means implies that these are the only systems addressed in the arts, but, as art is always both dependent upon and critical of greater culture, a focus on ideology and its role in the process of representation becomes crucial.

The phenomena under discussion are Italian. This is partially an accident of geography but it also reflects the galvanic atmosphere that has characterized artistic production on the peninsula. Forming the conclusion of this essay, is the Italian architecture of the modern era and that architecture's peculiarly rich affirmation of the continuing significance of position and sensation in a charged contemporary climate. In Italy the bonds between art and greater culture are omnipresent and the discourse concerning them is particularly rich. The line from politics to representation is direct. One of the most available vehicles for this transfer is through the body - through its location and interaction with artifacts. In Italy, where both the senses and the intellect are uniquely encouraged, it logically follows that the unrivaled plethora of artistic material should be so readily available to a criticism predicated on the belief that sense and memory are coeval with reason and knowledge.

In Medieval painting, symbolic rather than actual relations -imagery supporting a semantics stressing the eschatological charge of the world presented - deny engagement of the viewer in the allegorical action of the image. The living observer is presented with another world only awakened to after the illusion of this sphere is transcended. The representation of a mountain, fully cognizant of its purely symbolic function, can appear half the height of a man who seems to stand behind it, yet they simultaneously occupy the same plane. The work of Medieval artists shows a parallel place where the laws of physics or of optics, where the very laws of physical relations themselves, are superseded. The actual plane of the picture remains evident and sacrosanct. Argan' finds that Medieval architecture, largely ecclesiastical in purpose, adhered to this model as well.

With the reformulation of perspective during the early Renaissance, the engagement of the actual and temporal found a renewed medium. The house of the painter Andrea Mantegna in Mantua $^{2}$ presents a lesson in Renaissance attitude. The plain mass of the building contains a doubletiered cortile. Its inner ring, corresponding to the building's main floor, is cylindrical. The court's second tier is square in plan. This level would describe a cube in volume if it were to continue to the ground around the cylinder.

Here position reveals a deep involvement of systems of representation and the corporeal with the intellect. If the viewer lies with head and eyes at the center of the marked pavement of the circular court, in his or her cone of vision, the cornice of the inner drum precisely frames that defined by the edge of the outer cube. Thus the carefully calculated perspective that determined the related proportion of the two courts places the body of the viewer, through the interpretive power of thought, within the square and circle, becoming Leonardo's Vitruvian figure. Body sense is synthesized with visual cognition and the figure is resolved - a perfect Renaissance lesson, involving the powers of synthetic reason, the laws of perspective, the charged symbology of perfect geometries, systems of proportion and physical centrality and, most importantly, bodily awareness in counterpoint with theoretical precision. In the void at the center of his own house, Mantegna, the scientist of composition and reference, fashioned a participatory ensemble that elucidates the bond between awareness and ideology that was so central to his era's sense of itself. 


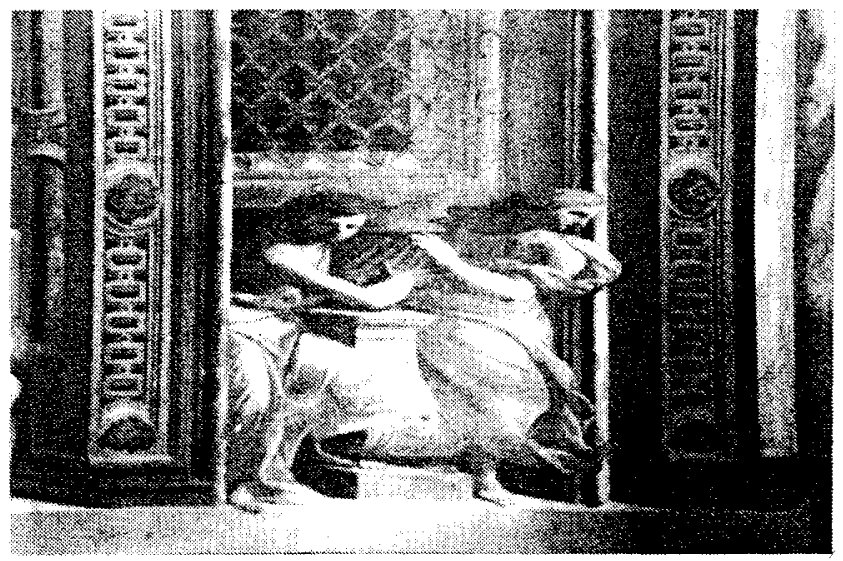

The elaborate painting schemes for the church of San Ignazio and the rooms of Loyola at the Gesù, both in Rome, make obvious the discipline of position implied by such quadratura representation. Their author, the Jesuit Andrea Pozzo, decorated the grandiose temples erected by his young and exuberant order at the end of the 17th century, and these buildings relied especially on their painted motifs to project the appropriate propaganda fide. Saint Ignatius' was an order determined by a series of devotional actions defined in his Ejercicios espirituales. These positioned the practitioner, through activity of both body and consciousness, to receive enlightenment and indoctrinate others. Many of the exercises' prescribed actions were simple and repetitive. While often eschatological in focus, they were physical by analogy. They required the assumption of certain precise positions making possible correct contemplation and providing specific views into the ecclesiastical firmament. Roland Barthes writes "Ignatius has linked the image to an order of discontinuity, he has articulated imitation, and he has thus made the image a linguistic unit, the element of a code."

At San Ignazio, Pozzo covered the ceiling of the nave with an enormous tromp l'oeil of Loyola ascending through a turmoil of painted architecture and allegorical figures representing the triumph of The Allegory of the Missionary Work of the Jesuit Order, restating the tree of enlightenment to which Barthes likens the exercises themselves. However, these are only seen as correct in perspective, and continuous with the appropriately Baroque architecture of the church, from a single point marked by a yellow disk inlaid in the floor at the center of the space. For the uninitiated visitor arriving at the designated point, the distortions and confusions of the ceiling are suddenly and forever resolved and the composition becomes clear. Similarly, the almost flat panel above the crossing is painted to appear as if it opened into a grisaille dome with light pouring in through windows in the illusionistic drum. Again, a disk in the floor marks the point at which this realistic and entirely architectural composition aligns itself with the rest of the building. The lucid privileged point of orientation is not, as it is for the nave painting, at the center of the space. Instead the correct view of the resolved dome is from an angle toward the front door of the church, placing the positioned viewer among the congregation. Pozzo's illusion doubly unfolds as the phenomenal space of the dome distorts and resolves. Deleuze's "infinitely folded form" is exaggerated by the nature of the painted text.

In the hall that leads to the rooms of Saint Ignatius at the Gesù, anamorphoses mask a space that is polygonal in plan. The painting offers the illusion of right angles and symmetry, but, more importantly, it initiates before entry into those special rooms. Two points, marked in the floor at either end of the room, position the viewer to understand the projected painting of distorted architecture and deformed figures as a resolved and orthogonal hallway, as an ordered foyer to the saint's rooms.

In anticipation of worship at San Ignazio, or entering the chamber at the Gesù, through the arrival at those marked spots, that which was muddled becomes clear. A miracle of ordering occurs, in proximity to Ignatius and his doctrine. This then is another of the exercises, in the Jesuit manner, another ritual action toward understanding, involving intellect, vision and body. By finding the correct position, by making the appropriate action, the viewer arrives at perception. ${ }^{5}$ The confusing appears clear and a spiritual message is delivered by analogy to the physical.

Pozzo wrote, paraphrasing Loyola, in his treatise for architects and painters "Therefore, Reader, my Advice is, that you cheerfully begin your Work, with a Resolution to draw all the lines thereof to that true Point, the Glory of GOD." Clerics often painted anamorphoses and, beyond their bizarre and hermetic cleverness, these compositions were clearly didactic devices promising faith and working in the medium of physical perception.

In the New World, the Jesuits extended the discipline of position, exemplified in anamorphosis, to the scale of the city. The colonial-evangelical settlement among the heathens, called the "reduction," was, in its planning and through the routines implied by that plan, a didactic ensemble. Cities have perhaps always been that, places of socialization and, more explicitly, hierarchical exhibits of and for the polis - theaters of culture in which the citizen acts and is simultaneously acted upon. The "reductions", in the unambiguous position of all urban elements - dwelling, church and state - were literal machines for "reducing" both the colonized and the colonizer through the physical lessons of urban life. Like the anamorphoses, the divine city instructed as the continuously positioned resident understood the significance of its elements. Daily life and its habitual patterns enforced rituals of spiritual and political obedience.

In the two decades after 1922, the Italian Fascists had more time to build than did their German colleagues and somewhat less destructive force directed at them during the war that ended their regime. The resulting ensembles that survive throughout Italy deliver an unequivocal message coupled with simultaneous associations to ancient Roman tradition and Futurist dynamics.

At the Casa del Fascio in Como, the entrance phalanx of 


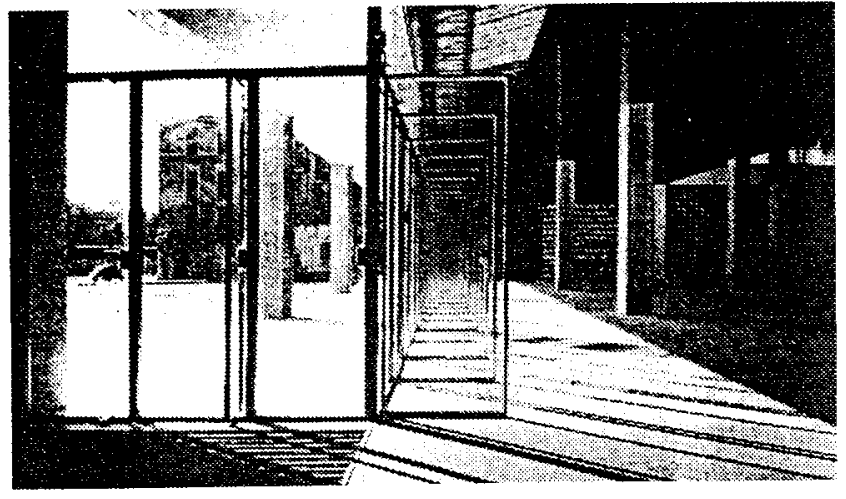

glass doors at the ground floor opens to include the piazza within the body of the building. Terragni's "glass house" merges the charged space of the city and the Fascist building. The lines of columns become the first in the ranks of the loyal, equating the physical fact of the individual and the perceived presence of the mass movement - its endless armies and ceaseless power. Like the hypostyle mosque, with its forest of columns stretching in all directions, ratifying the single devotee within the mass of the worshipful and simultaneously implying the intrinsic and equal enfranchisement and subservience of that mass, the Casa de Fascio conveys a contradictory message of personal self-affirmation and total anonymity within the absolute force of the regime. It "interpellates," in the sense of Althusser, as it subsumes, thus reifying one of the doctrinal deceptions that led directly to the success of Fascism, and, to some extent, to all dominant ideologies.

Much of the elemental force of the Casa Malaparte on the Capo Massullo in Capri derives from its massing and position. It is a simple brick bar molded like a slug to the sharp contours of the promontory's thin profile. This bar is elaborated as a widening stair ascending to a plane without parapet. It is an alarming space where the poet works without borders, and without a net.

At the Casa Malaparte the critical sentiments and ideologies of a charged epoch are compressed, with special intensity and a rare physicality. ' The elements of the "casa come $m e$ " clearly derive from Malaparte's memories and obsessions. Like the House of Mantegna, this project brilliantly interprets a sophisticated but architecturally naive vision, this time that of a writer, in a composition of striking directness and depth.

The mass of the building is a foundation for the empty floor at the top of the stair. Adalberto Libera's initial design confirms this as a first intention and the finished building is a podium. ${ }^{8}$ The piano nobile is framed by the horizon. The Tirrenean Sea and the Gulf of Salerno are the backdrop for the players in this theatrical salone. Meanwhile, the massive body of the house consciously evokes the space of incarceration and exile. Malaparte wrote "I feel like a bird that has swallowed his cage. I take my cell with me, inside me."

Luigi Moretti's career spanned World War II. His work for the Fascists displayed a particular latitude given the powerful stylistic criteria imposed by the regime. The Casa della Gioventù, built in 1933 in Rome, employs subtle effects to strengthen its political-aesthetic argument. The tower faces the Tiber. Emphatically, this element is the face of the building, replacing a more conventional concept of facade in this Elementarist composition. It organizes and represents the complex ensemble behind it. While it appears as a simple flat shaft topped by a flange canopy, in fact the tower has a slightly curved edge, converging toward the center as it nears the top. It has entasis. Thus the tower is a pilaster, or a sectioned column, and the flange a capital. The body of the enthusiast and that of the column $=$ building $=$ regime $=$ empire are compared. As if to accentuate the typically Fascist semantic mix, here Moretti juxtaposed a glazed corner stairwell, of impeccable Bauhaus purity, to the eccentric entry-column.

Moretti was one of few important Italian architects who did not reverse his political sentiments after 1945, but, in his designs of the post-war period, the prevailing Expressionist and Neo-Realist reactions that followed the collapse of Fascism gave license to a personal tendency toward the caprices already evident during the ' 30 s. These remained particularly syntactic, however, making reference through manipulations of materials, visual games or transformations of the abstract elements of architectural form -planes, masses, punctures, etc. Not surprisingly, Moretti's designs were much less literal in their emulation of the vernacular than were those of his contemporaries more committed to discovering a popular architectural semantics. His was a stylistic reaction to political shifts that he did not follow and his work was particularly compositional, uncommitted and open to appropriation by market forces. Along with his other buildings of the immediate post-war period, Moretti's Casa Girasole in Rome is a riot of allusion and, as well, employs anamorphosis and distortion in a composition which joins those of Libera, Gio Ponti, Giovanni Michelucci, Carlo Mollino, Ernesto Rogers and other survivors in a proposal for a distinctly Italian form of exuberant Modern eclecticism during the two decades following 1945. At the Girasole, the front elevation extends beyond the confines of the plan, hanging over the street, in a theme of the weightless, white, machine hovering over the atavistic base that he repeats in his extraordinary Astrea housing block in Monteverde Nuovo of 1949 and in the tour-deforce mixed-use complex on the Corso Italia in Milan of 1953. The façade of the Girasole is composed of sliding screens on tracks, in an elaborate discussion of face, mask and façade. The contorted body of the building floats over a primal tufa base. Here fragments of antique sculpture embed in the stone and self-consciously reiterate the omnipresent Roman palimpsest.

Of particular interest, at the Girasole, is the fissure in the facade above the entry vestibule. The sides of the slot in plan, and the lower edge in elevation, break into two angles so that the viewer sees, upon approaching the building, a space that seems to change in surface, in an anamorphic gesture worthy 
of Pozzo. At a certain viewpoint either wall of the slot seems flat, due to the conjunction of angles, while at others the same walls obviously fold at their center. The space is another of the building's continuous distortions. While the polemic is similar to that presented by Pozzo, this time it is decidedly secular. The design stresses position within the ideologically charged atmosphere of contemporary Italian design.

My colleague at Tulane, Scott Bernhard, associates these projects with the contemporary obsession with the airship, in particular the dirigible, evident in the suspended slabs of orthodox Modernism. Following this reading, then the floating vessel of the Roman projects, the enthusiastic inflated suspension of the immediate post-war has crashed by ' 53 in the Milan complex and sits resignedly on the residentialoffice complex in a recognition of the triumph of commerce and material, that distinguishes post-war Milan from the more delirious and ancient metropolis to the south, and which distinguishes the heady climate of the dopo-guerra from the more pragmatic and compromised $50 \mathrm{~s}$.

At the explosive beginning of the Industrial Revolution, as cities dilated and cultural mechanisms became unhinged, new functional-rhetorical requirements (for train stations, festival halls, public museums and libraries) were predicated by the inversion of architectural hierarchies, serving the freshly dominant bourgeoisie and placating the spectral masses. Along the crowded heterogeneous boulevards there appeared certain significant diversions. The arcades furnished the ambulatory city with covered pseudo-streets devoted to consumption and the promenade. Within the anarchy of the modern, public parks injected the tamed nature appropriate to the bourgeois idyll. ${ }^{10}$ And panoramas became common entertainments, along with the invention of photography and the concomitant crisis in the mimetic arts. "The public, or at least those who could pay the modest admission, entered a drum of realistic painting. Sometimes this false world was fantastic in nature, a city (St. Petersburg, Cairo, New York, Constantinople) that would never be visited, or was pictured from a viewpoint that could not be attained, but as often the scenes presented were from just beyond the doors of the panorama-of the same city from an available rooftop or from the main square. Inside was the marvelous illusion of known reality. In the panoramas it was not the image's fantastic nature as much as the force of pure technique, of simulation, that awed the visitor. Possibly, it was the illusion itself that appealed so strongly: the sense of removal from, and consequent control of, the tough facts of the extraordinary new metropolis. Like the filmgoer, the flâneur was centered in a city re-presented and could feel finally positioned, as at the House of Mantegna, rather than lost in the crowd or ultimately peripheral in a world a-tilt. The panoramas fulfilled desire unrequited in the modern age.

...for the perfect flâneur, for the passionate spectator, it is an immense joy to set up house in the heart of the multitude, amid the ebb and flow of movement, in the midst of the fugitive and infinite. To be away from home and yet to fell oneself everywhere at home. - Charles Baudelaire ${ }^{12}$

As movie-houses replaced panoramas, the space of representation became more absolute. Painted space, the conventional narrative medium, gave way to filmic space.

At the new town of Sabaudia, built in 1934 on the justdrained Pontine marsh south of Rome, the typical Fascist combination of traditional and futurist figuration dictated a town plan that was simultaneously Modernist and incorporated the established relations of monumental buildings and figural spaces that characterize conventional Italian urbanism. Two roads that meet, not at a single intersection but at four, define the town center. The center of the town is thus not a point but a quadrant defined by this shearing kardo and decumanes. Held in the center of the small city is neither the church nor city hall. Here, instead, are the casa del fascio and the cinema, buildings more crucial to the regime than the conventional seats of power. The movie-house, the voidmonument at the heart of the new town, is the space of propaganda and gathering, substituting for the peripheralized

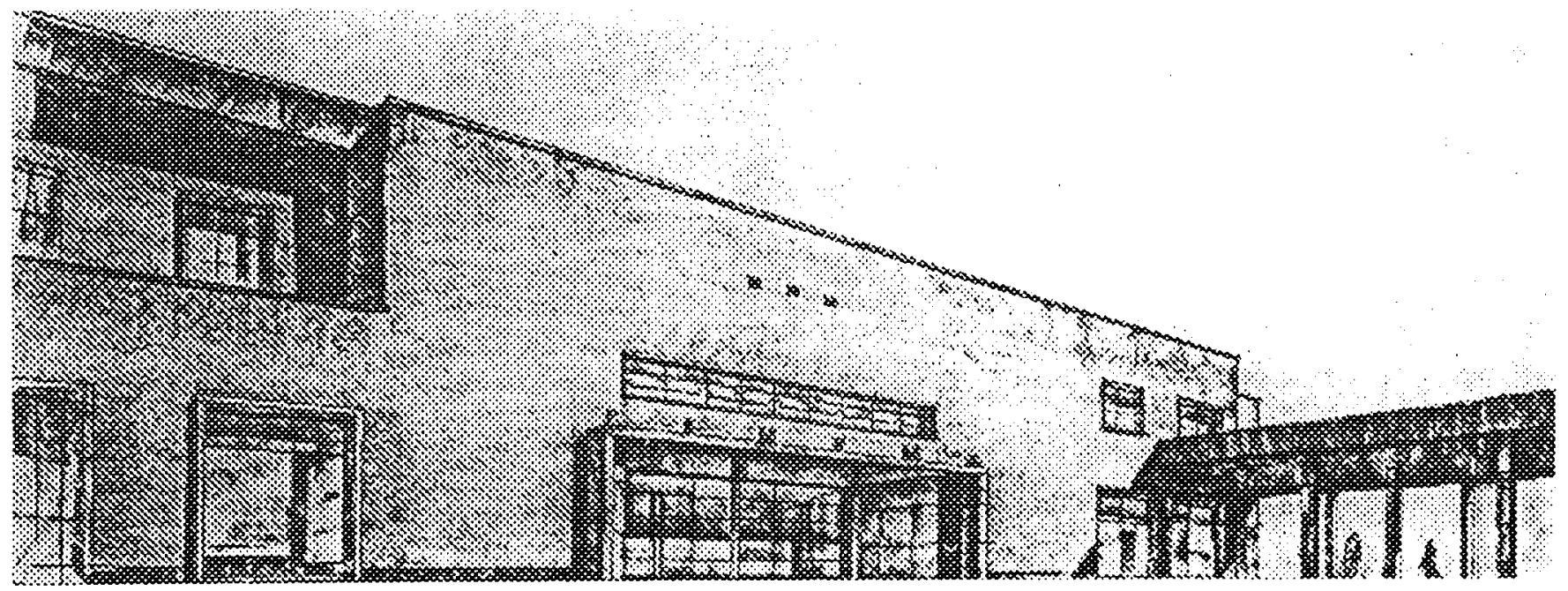


nave and city hall chamber and, to some extent, substituting for the piazza itself. A radical departure from the presumptions of traditional Italian civic space is presented. After experiencing the stiff monuments of the city, like Morandi or Sironi in their contrived stillness, the viewer absorbs the propaganda and allegories that re-define culture in a dark non-space, seated facing the screen, alone with the image. He or she is denied the communal-familial sense that defines the customary social realm, and which it was formerly the duty of architecture to orchestrate.

The eschatology of Medieval representation again has been achieved. Another world is presented and this sphere is superseded. But now the invitation is total to enter...and be influenced by...the other. The indoctrination envelops. The viewer is not set apart from a didactic assembly of symbolic forms, but floats instead in a dark void and enters and is consumed by the image while simultaneously consuming. The mirror of the screen creates its own double in the dark of the movie-house. ${ }^{13}$

In Medieval representation, including architecture, the viewer and the object remain in separate realms, linked by aspiration. The Renaissance depicts the spaces united, as they were for a short time in Roman painting. This linking persisted into the 19th century both in painting and architecture. In the modern age, film and video, the dominant media, subsume the space of the viewer within that of the image. This commanding representational discourse now seems to diminish the historical relations of body and artifact, while potentially proposing new ones.

Our era, while presenting potentially exciting new criteria and dramatic shifts in alignment, does not limit as much as reframe the possibilities of a discourse predicated on the interaction of perception with space, view and the forms of power. The modern revolutions in attitude regarding these basic criteria of representation propose an expanded field. The conditions first outlined in this essay - narratives of position and sense as perceived rather than received and the inevitable conjoining of these systems of reference to ideology - seem to survive and even to thrive. The continuity of these conditions, recognizing the unavoidable alterations in viewpoint discussed in this essay, seems one of the strongest arguments for the viability of architectural work at a time when such arguments are sorely needed, as so many others become increasingly garbled or marginal. Perhaps the very forces that call for a reassessment of roles and bring about changes in viewpoint also enliven an architectural continuum constantly in need of critique.

\section{NOTES}

1 Argan, Giulio Carlo, "The Architecture of Brunelleschi and the Origins of Perspective Theory in the Fifteenth Century" Journal of Warburg and Courtauld Institutes Vol. IX, (London, 1946) pp. 96-121

2 This building, from the late 1460 's, seems to have been a collaboration between the artist and Giovanni da Padova.
${ }^{3}$ Barthes, Roland, Sade, Fourier, Loyola, trans. Richard Miller (U. of California: Berkeley, Los Angeles, 1976) p.56

4 "The law of the cupola, a Baroque figure par excellence, is double: its base is a vast ribbon, at once continuous, mobile, and fluttering, that converges or tends toward a summit as its closed interiority. The apex of the cone is probably replaced by a rounded point that inserts a concave surface in the place of an acute angle. It is not only in order to soften the point, but also because the latter must still be in an infinitely folded form, bent over a concavity, just as the base is of a matter that can be unwrapped and folded over again."

Deleuze, Gilles, The Fold: Leibniz and the Baroque, (Minneapolis: U. of Minnesota, 1988) p.124

5 "What I think distinguishes Loyola's procedure, even with regard to the forms of devotion of his own time, is the shift from the word to the visual image as a way of attaining knowledge of the most profound meaning. Here too the point of departure and the point of arrival are already established, but in the middle there opens up a field of infinite possibilities in the application of the individual imagination, in how one depicts characters, places, and scenes in motion. The believer is called upon personally to paint frescoes crowded with figures on the walls of his mind, stating out from the stimuli that his visual imagination succeeds in extracting from a theological proposition or a laconic verse from the gospels."

Calvino, Italo, Six memos for the next millennium (New York: Vintage, 1988) p. 86

- Pozzo, Andrea, Perspectiva pictorum et architectorum, 1793 from Martin, J.R., Baroque(New York: Harper \& Row, 1977) p.174, quote from English edition of 1707 Rules and examples of perspective proper for Painters and Architects.

7 The eccentric form of the Casa Malaparte, but also the plethora of mannered detail, from the fireplace window to the furnishings and materials, seem to satisfy the author's taste for the bizarre and extreme, evident in his writings. The contributions to the villa of Savinio, Fazzini, Tamburi, and the most mannered architect of the period, Luigi Moretti, also encourage a "magical" interpretation of the project as do Malaparte's writings.

${ }^{8}$ Like Malaparte's prose, Libera's designs engage in semantic play and tense formal juxtapositions that also verge on the surreal. A collaboration between these two artists indeed seems serendipitous. Particularly appropriate for comparison is Libera's post office in the Porta San Paolo in Rome completed several years before the work at Capri began. This building superimposes reference systems. The outer block of the building, its white surface and the neutrality of square windows, appears to conform to the rationalist rigor of Gruppo Sette and MIAR (Movimento italiano dell architettura razionale), the Rationalist avant-garde, in both of which Libera had been an active member. First perceptions seem peculiarly compromised by the crossing diagonals of the spandrels and mullions in the stairwells at the block's most prominent forward extension. The woven marble screen that covers the windows at the back of the post office likewise tests the implied purity of the outer block. The marble skin itself, in the slight but intentional unevenness of its laid-up stone surface, brings into question the absolute austerity of the mass. Held within this frame is the public hall, sits an oval civic room like the nearby Circus Maximus and Piazza Navona. Its own stainless-steel structure carries this object-space and it protrudes glistening from within the arms of the surrounding icy stone block. In front of these elements is a portico that extends beyond the mass on either side. This arcade, originally clad in contrasting black marble, was intentionally disengaged with its own structural grid. Leading from the boulevard to the implied edge made by the portico is a wide 
stair-ramp formerly set between pools. These elements do not resolve or harmonize. They juxtapose, sitting in the sort of adjacency typical of contemporary photo-collage, and like that revolutionary and critical medium, they indulge in the semantic friction that such adjacencies must intrinsically produce.

${ }^{9}$ Malaparte, Curzio, Fughe in Prigione (Firenze, 1943)

10 The Crystal Palace combined these two new types, placing an arcade in Hyde Park, a greenhouse-temple encyclopedically dedicated to the commodity fetish.

11 Homage to Walter Benjamin and his essays, "Paris -- Capital of the Nineteenth Century" (for the section on panoramas) and "The Work of Art in the Age of Mechanical Reproduction", is automatic here, and the issue of "aura" seems central to the discussion of the change in attitude implied in the shift from narrative painting to film and the crucial perceptual differences implied by such a shift. The text must be seen as irrevocably altered due to the replicability implicit in cinematic depiction ("appearing on 700 screens!!") and the accompanying interpretive closure brought about first by the actual depiction of movement and later of sound, and the final dissemination of image possible with television (billions can share the same image, controlled and finite information infinitely dispersed). Also the epistemology carried forward by Benjamin should be seen as a necessary subtext to any discussion of the inevitable links between society and its artistic manifestations. As Benjamin pointed out, cultural criteria are necessarily material.

${ }^{12}$ Baudelaire, Charles, The Painter of Modern Life and Other Essays (New York: Phaiden, 1964) p.9

${ }^{13}$ See the analogy of the mirror in Foucault, Michel, "Of Other Spaces - the principles of heterotopia" Diacritic 16, No.1 (Baltimore: JHU Press, 1985) 